\author{
DERIVATION \\ $O E$ 개는 \\ FLORA OF HAWAII \\ CAMPBDLL
}

Dow or

Toresinged

Llominat 



LELAND STANFORD JUNIOR UNIVERSITY PUBLICATIONS UNIVERSITY SERIES

\section{The Derivation of THE}

FLORA OF HAWAII

BY

\section{DOUGLAS HOUGHTON CAMPBELL}

Professor of Botany

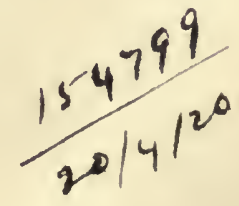




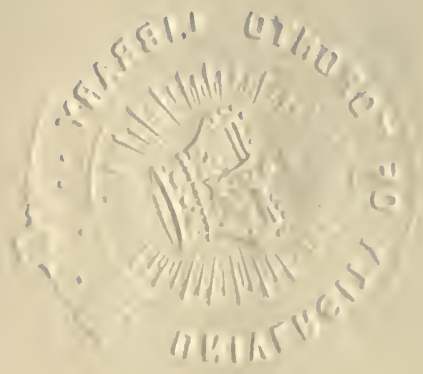

Stanford University

PRISS 


\section{CONTENTS}

Theories as to the Origin of the Hawaiian Islands................................... 5

Topography of the Islands.......................................................................... 6

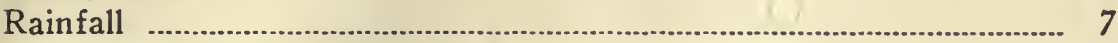

Botanical Regions of the Islands............................................................ 8

Predominance of endemic species, and relation to the Southern Pacific

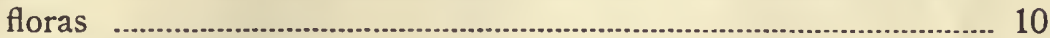

Algæ, Fungi, Bryophytes..................................................................... 11

Pteridophytes ...................................................................................... 14

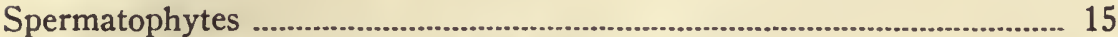

Guppy's theory as to origin of the Hawaiian flora.................................... 17

Strand Flora ............................................................................................ 21

The possibility of a former land connection between Hawaii and the South Pacific .................................................................................. 21

Indo-Malayan, Australasian and South American elements in the flora 22 North American elements of the flora....................................................... 23

Absence of certain types; possible extinction of species ; conclusion...... 24 Tables showing the relative numbers of American and AustralasianMalaysian genera ............................................................................. 25

Fauna of Hawaii, molluscs, insects....................................................... 28

Arachnida, marine invertebrates............................................................ 30

Vertebrates …....................................................................................... 32

Conclusion ............................................................................................. 34 
Digitized by the Internet Archive in 2007 with funding from Microsoft Corporation 


\section{THE DERIVATION OF THE FLORA OF HAWAII}

Owing to their extreme isolation, the Hawaiian Islands are of special interest both to the geographer and the biologist. With a combined area of 6,454 square miles, they are further removed from any continental area than is any other region of equal size upon the globe. They are 2,000 miles from North America, the nearest continent, and the nearest islands of any importance, the Marquesas, are 1,860 miles distant.

There are two very different views held as to the origin of the archipelago. The one most commonly accepted is that the islands, which are entirely volcanic, were thrown up by volcanic activity from the ocean depths, and that they have always been completely isolated. At present the archipelago is surrounded by very deep water. Within forty miles of the shores the ocean is upward of 10,000 feet in depth, and between the islands and the American coast is an enormous area of deep water, in places reaching more than 20,000 feet in depth.

It is believed by some students of the subject, however, that the islands have not always been so isolated as at present. This view has recently been taken by Pilsbry. ${ }^{1}$ The advocates of this theory believe that there was formerly a much larger area of land in the Pacific, including Hawaii, which was connected more or less intimately with the great land masses of the Southern Pacific, now represented by Australasia and Indo-Malaysia. The multitude of islands constituting Polynesia is believed to be merely the remains of a once extensive land mass,-either a single continent, or several large continental islands, like Australia. This great continental area has been undergoing subsidence since early Tertiary times, and the islands now existing are the tips of mountain masses,-often volcanic,-superimposed upon this submerged continental area.

Should this latter hypothesis prove correct, we must assume that the large volcanic masses, rising to nearly 14,000 feet in the case of Mauna Kea, have been formed upon a land area which has sunk in the course of ages as many feet below its former level, since on nearly all sides the archipelago is at present surrounded by very deep water.

To the northwest of the main group there extends a chain of small islands evidently formed along the same line, and connected by relatively

1 Pilsbry, H. A.: "Mid-Pacific Land-Snail Faunas," Proc. Nat. Acad. Sci., 2, 429-433. 1916. 
shallow water with the main group. There are also to the west and southwest somewhat shallower areas connecting with the Polynesian region to the southwest.

As might be expected from their extreme isolation, both the fauna and flora of the islands are very much specialized, and the question of the origin of the organisms now inhabiting the islands is one of the greatest interest.

If the islands have been thrown up as isolated volcanic masses from the ocean depths, it necessarily follows that, except for the comparatively small number of plants and animals introduced through human agency, all the organisms must have reached the islands from very remote regions by such accidental means as air currents, ocean drift, or migratory birds. The present indigenous plants and animals must be, according to this theory, the descendants of such chance immigrants.

On the other hand, if an ancient connection with some former large land area is admitted, we may assume that the majority of the organisms are the descendants of species which existed at the time when this land connection was severed.

The Hawaiian Islands lie between $18^{\circ} 55^{\prime}$ and $22^{\circ} 15^{\prime}$ north latitude and $154^{\circ} 50^{\prime}$ and $160^{\circ} 30^{\prime}$ west longitude; and there is also a chain of small low islands and reefs extending for about $18^{\circ}$ in a northwesterly direction. The whole chain of islands comprises in reality the summits of a great submerged range of mountains apparently formed as the result of enormous volcanic activity along a fissure in the earth's crust, which began at the northwest and has proceeded in a southeasterly direction, the last manifestations of activity being now found only in the active craters of Kilauea and Mauna Loa, in the Island of Hawaii, the largest and most southerly member of the archipelago.

Except for certain coral formations, the islands are of exclusively volcanic composition, and the soils everywhere composed of disintegrated lava or volcanic ash.

In marked contrast to this uniformity of soil constitution are the conditions of temperature and moisture, due to the mountainous character of the islands and the prevailing northeast trade wind. On the windward side there is a very heavy precipitation, and the erosion results in deep, narrow valleys, with precipitous walls, the vertical cliffs, or "palis," being a marked feature of those valleys, which usually end abruptly against a high cliff over which descends a waterfall. On the leeward side, especially in the loftier islands, the precipitation is very light, and the ancient lava flows sometimes have remained scarcely changed for centuries. A very remarkable instance of this is seen in the huge extinct crater of Haleakala, on the Island of Maui. There is no record or tradi- 
tion of any activity within this crater, which is sheltered on the windward side by walls 2,000 feet or more in height. The floor of the crater shows lava flows that look as if they had been formed yesterday.

From a study of the topography as well as of the fauna and flora of the different islands, ${ }^{2}$ it is generally agreed that Kauai, the northernmost of the main group, is the oldest. The next large island, Oahu, upon which is situated Honolulu, has two mountain ranges of different ages, one, the Kaala range, being probably of about the same age as Kauai. The main range of Oahu is more recent, and the Island of Molokai is of about the same age.

Maui, the second in size of the islands, is composed of two unequal portions, a smaller and older part, West Maui, connected with the larger, much more recent part by a low isthmus. The greater part of Maui is composed of the great extinct volcano, Haleakala, over 10,000 feet in height. The vast crater is over twenty miles in circumference and 2,000 to 3,000 feet in depth, and although the lava flows and cinder cones within the crater look as if they had been formed very recently, there is no tradition among the natives of any eruptions.

Much the largest of the islands is Hawaii, which comprises about two-thirds of the total area of the archipelago. It is composed of three volcanic masses of different ages. The oldest region is the Kohala range, which is much worn down. Next is the great cone of Mauna Kea, 13,805 feet in height, the loftiest mountain in Polynesia. There is no record of activity in this mountain. At the present day the volcanic activity is confined to the two craters of Mauna Loa, but a lower cone, Hualalai, has been active within a century. The summit of Mauna Loa is nearly as high as Mauna Kea (13,675 feet) and is occupied by an active crater. On the flank of the mountain is the great pit crater, Kilauea, now a familiar sight to the tourist. Hillebrand ${ }^{3}$ summarizes the formations of the islands as follows, in point of age: 1, Mauna Loa; 2, Hualalai; 3, Haleakala; 4, Mauna Kea; 5, Kohala range (Hawaii) and West Maui ; 6, Molokai and main range of Oahu; 7, Kaala range of Oahu, and Kauai.

Considering the latitude, the temperatures are very moderate. In Honolulu, at sea level, the highest temperature recorded from 1904-1909 was $86^{\circ}$, the lowest $56^{\circ}$.

\section{RAINFALLL}

The precipitation shows extraordinary variation within short distances. While in Honolulu the annual rainfall is only about thirty inches, in the valleys a few miles back of the town it may be more than four times

${ }^{2}$ Hillebrand, W.: "Flora of the Hawaiian Islands," Introduction, pp. xviiixxii. 1888.

${ }^{3}$ Loc. cit., p. xxi. 
as much. On the lee shore, southeast of Honolulu, the precipitation is much less than in the town, and extremely arid conditions prevail.

The maximum rainfall in the islands is on the windward side at elevations of 4,000 to 6,000 feet, where some of the heaviest rainfalls that have been recorded anywhere occur. The most extreme case of which we have been able to obtain records is on Kauai, where on the highest summit of the island, Mt. Waileale, a five-year record showed a mean annual rainfall of a little over 500 inches!" Less than fifteen miles from this station, in Waimea, a village on the lee shore, the annual rainfall is not much over twenty inches, and there are other localities where it is much less.

The rainfall is almost incessant in the wettest regions, and is not confined to any special season of the year.

This extraordinary range of precipitation, and the great differences in elevation and exposure, naturally have been important factors in the development of the vegetation.

Unfortunately, much of the original vegetation has disappeared since the advent of the white man. During the past twenty-five years nearly all of the available land at the lower elevations has been brought under cultivation, and the forests have entirely disappeared. The ravages of cattle, and in the drier parts of the islands, of goats, have entirely denuded large areas that not many years ago were covered with forest. Through these agencies there is no question that certain species have been quite exterminated. Moreover, the introduction of many foreign plants, which have become quite naturalized, has entirely altered the aspect of the vegetation in the lower levels.

\section{BOTANICAL REGIONS}

The different botanical regions have been treated recently at some length by Rock. ${ }^{5}$

He recognizes six principal types of vegetation: 1, The Strand Flora; 2, The Lowland Region; 3, The Lower Forest Region; 4, The Middle Forest; 5, The Bog Region; 6, The Upper Forest.

The strand flora of Hawaii is poor when compared with that of most tropical regions. It comprises a number of cosmopolitan species, like Ipomoea pes-caprae and Hibiscus tiliaceus, but also has a considerable number of endemic species. ${ }^{6}$

4 See Science, Nov. 23, 1917, pp. 511-512.

'Rock, J. F.: "The Indigenous Trees of the Hawaiian Islands," pp. 1-87.

- McCaughey, Vaughn: "The Strand Flora of the Hawaiian Archipelago, Geographical Relations, Origin, and Composition," Bulletin Torrey Botanical Club, 45, 259-277. 1918. 
The lowland zone varies much in different parts of the islands. Many of the strand plants invade this zone, but many others are largely confined to it. On the leeward side this is largely grass land, except where it has been invaded by lava flows, but in some places it is so dry that the bare lava is quite destitute of vegetation. This zone, especially in Oahu, has been invaded by certain introduced plants, notably prickly pear and "Algaroba" (Prosopis). The latter, a leguminous tree, forms extensive groves and is of great importance both for the wood and for the edible pods, which furnish valuable food for animals.

Other introduced plants which have spread extensively, are the guava and a species of Lantana ( $L$. camara), the latter being a very troublesome pest. On the windward side of the islands the forest may come down to the sea.

Beyond the more or less open lower zone of vegetation there is found the lower forest region. On the windward side of the more lofty islands, and in the moist valleys of the lower islands, this forest is very dense, and composed of comparatively few trees. The predominant trees are the Kukui (Aleurites), and Ohia (Eugenia), both species common throughout Polynesia, and very probably introduced by the aboriginal immigrants. The drier parts of this lower forest, according to Rock, are very much richer in species of trees than the rain forest.

The middle forest zone, extending from about 2,000 to 4,000 feet, is extremely rich in species, and includes a great variety of interesting shrubs and some herbaceous species as well. Probably the most conspicuous tree is the "Ohia lehua" (Metrosideros polymorpha), also a widespread species of Polynesia. This mountain forest is the home of many of the most peculiar of the endemic plants, such as the tree-lobelias, and certain Rutaceae, e. g. Pelea. On the windward side of the islands this is a typical rain forest, and there is a great development of ferns, mosses, and liverworts. Here the tree ferns and the beautiful filmy ferns reach their best development.

\section{BOGS}

On the summits of some of the older mountains there are bogs of characteristic formation. These are particularly well developed on the high plateau which constitutes the greater part of Kauai. Here, at an elevation of 4,000 to 5,000 feet, there is a prodigious and almost incessant precipitation, converting the whole region into a trackless swamp largely covered with trees, but in places forming open bogs, covered with tussocks of grasses and sedges, among which grow a number of characteristic species, largely of northern affinities. Among these bog plants are the 
widespread Drosera longifolia, dwarf geraniums, violets, lobelias, vacciniums, Selaginella, Schizaea and others.

On the lofty mountains of Maui and Hawaii there is a forest zone reaching up to 11,500 feet, but this is much less varied than the middle forest.

As might be expected from the extreme isolation of the islands, both the flora and fauna are highly specialized, the proportion of endemic species being very great. According to Hillebrand eighty per cent of the vascular plants are peculiar to Hawaii, while no less than eighty-five per cent of the Dicotyledons are confined to the islands. The fauna shows very much the same high proportion of endemism. It is plain that whether or not there have been land connections formerly, the islands have been isolated for a very long period.

Among the most characteristic animals are the land snails, which have been collected assiduously and very thoroughly studied. As the result of his studies on these molluscs, Pilsbry ${ }^{7}$ came to the conclusion that they must have reached the islands at a very remote period, through some land connection, as they are quite unsuited to any conceivable form of transportation over such distances as now separate Hawaii from the mainland. They are inhabitants of the humid mountain forests, and apparently cannot survive exposure to heat and dryness, such as would be necessary in case they were transported from a distance by driftwood, as has usually been assumed to have been their means of introduction into the islands.

According to Pilsbry, they are all very old types, there being a complete absence of the more modern snails from the fauna. Their nearest relatives belong in Southern Polynesia, and these in turn are more distantly related to forms of the adjacent Asiatic shores and have nothing in common with American types. This indicates that the existing islands once formed a single, much larger area, which was presumably connected more or less directly to similar large areas in what is now Southern Polynesia.

The occurrence of certain plants identical with or closely related to those of the Southern Pacific areas presents the same problem as the land snails. There is a rich liverwort flora, including a number of species whose presence is hard to explain, except on the theory that they are remnants of an ancient continental flora. They are plants of great delicacy, often confined to the higher altitudes of the rain forest, where there is almost constant precipitation. Such species are incapable of sur-

7 Loc. cit. 
viving the heat and dryness of the lowlands, and their spores are not fitted for long periods of desiccation.

In the rain forest occur also a number of filmy ferns (Hymenophyllaceae), plants of extreme delicacy, which could hardly have reached the islands by any conceivable form of transport.

In view of these facts, the writer decided to visit the islands with the special purpose of collecting liverworts, to see to what extent they confirmed Pilsbry's conclusions derived from his study of the land molluscs. The results were strongly confirmatory, and it seemed worth while to look into the relationships of the higher plants, which brought out to a surprising degree the close connection of the flora, as a whole, with the Southern Pacific regions, especially Australasia and IndoMalaysia.

In a previous paper $^{8}$ the principal results of these studies have been recorded; and in the present paper it is proposed to extend these studies and to present the data derived from the animal life as well.

The algae and fungi are as yet too imperfectly known to make an entirely satisfactory comparison with those of other regions. A recent list of the algae published by Professor McCaughey contains a good many cosmopolitan species, as well as a considerable number of endemic ones. Of the non-endemic, but not cosmopolitan, species, the majority appear to be related to those of the South Pacific and Indian Oceans, but the data are too incomplete to make it safe to assume this without reserve.

\section{BRYOPHYTES}

The writer has not been able to secure satisfactory data as to the mosses of Hawaii, but the liverworts have received considerable attention from collectors, and the writer has devoted some time to collecting and studying these plants. Hepaticae are very abundant in the rain forest, especially at higher elevations, 3,000 to 5,000 feet. The liverworts are presumably ancient types, as is attested by their present distribution. The lower forms are delicate thallose plants of very simple structure. These are relatively few in number when compared to the leafy types"scale mosses," as they are sometimes called. The latter are evidently more specialized, and presumably more modern types than the thallose species.

The writer made collections of liverworts from several localities in

${ }^{8}$ Campbell, D. H.: "The Origin of the Hawaiian Flora," Memoirs of the Torrey Botanical Club, 17, 90-96. 1918.

'McCaughey, V.: "Algae of the Hawaiian Archipelago," Bot. Gaz., 65, 42-57; 121-149. 1918. 
Oahu and Kauai, and also on the windward side of Haleakala, on Maui, at an elevation of about 4,000 feet.

Probably the most conspicuous and one of the commonest liverworts is Dumortiera trichocephala, a species widespread throughout the IndoMalayan region, but which does not occur in the American tropics, where it is replaced by the cosmopolitan D. hirsuta, also occurring in Hawaii. The Hawaiian specimens of $D$. trichocephala differ in some respects from East Indian material from various localities, examined by the writer; but the differences are probably not of specific value. It occurs at lower levels in Hawaii than is usual in the Malayan region, probably due to the cooler climate of Hawaii.

Often associated with Dumortiera is another large and conspicuous liverwort, Wiesnerella denudata. This is a monotypic species, which at present is known from only three other localities, viz., Java, the Himalayas and Japan.

Both of these characteristic Asiatic species inhabit very moist, shady localities, often on dripping cliffs or rocks along water courses, and they would not seem to be well adapted to dispersal over wide areas of land, let alone such expanses of ocean as lie between Hawaii and the Southern Pacific.

Quite as significant, perhaps, is the occurrence of certain so-called "horned liverworts" (Anthocerotaceae). Two of these, Megaceros and Dendroceros, are inhabitants of the rain forest. The latter was collected only at elevations of about 4,000 feet, where the rainfall was almost incessant. It is an epiphytic plant of extreme delicacy, and its thin-walled green spores germinate immediately on ripening, and are quite unfitted to survive even short exposure to the heat and dryness of the lowlands. Megaceros is a larger and more robust plant, but is always confined to moist and shady localities. Like Dendroceros, the delicate green spores germinate immediately, and seem quite unfitted for transportation by wind over any considerable distances, and the same may be said of the majority of the liverworts of the higher rain forest. ${ }^{10}$ The common species of Megaceros is very similar to a species widespread through the Malayan region.

Stephani's Index Hepaticarum ${ }^{11}$ shows that aside from the endemic and cosmopolitan species, the Hawaiian liverworts are almost exclusively species occurring in Southern Polynesia, Australasia, or Indo-Malaysia, as there are only two American species which do not also belong to this Old World.

${ }^{10}$ Campbell, D. H.: "On the Distribution of the Hepaticae," New Phytologist, 14, 203-212. 1907.

11 Stephani, F.: “Index Hepaticarum," Bull. de l'Herbier Boissier. 1898-1908. 
The only likely means of transport for the spores of most species would seem to be in mud adherent to the feet of rapid-flying migratory birds. As there are at present no migrants from the south, not to mention the great distance of the nearest source of supply, it is doubtful whether this will explain the presence in the islands of the numerous Asiatic and Australasian types. It is possible that some of the wideranging sea-birds might reach Hawaii from the Southern Pacific, but it is highly improbable that these would carry spores from plants living in the depths of the mountain forests.

It is interesting in this connection to note a remarkable case of a Hawaiian liverwort (Lepidozia sandvicensis) which Professor A. W. Evans writes me occurs also in Alaska. The most common migratory bird of the islands is the golden plover, which regularly migrates in large flocks from Alaska. It may well be that this bird may have been the agent by which this liverwort was transported to Alaska, and also the means by which some of the American immigrants, like the Chile strawberry, may have reached the islands. All of the known migratory birds are American, and could hardly have played a role in the introduction of species from the South Seas.

Stephani ${ }^{12}$ gives about seventy-five species for Hawaii, but his list is incomplete, and it is safe to say that the total number recorded up to the present is about one hundred. Of these, about twenty per cent are thallose forms, the remainder belonging to the foliose Jungermanniales. Omitting the Anthocerotaceae he lists seven species of Marchantiaceae and twelve thallose Jungermanniales. Of the former, one species is cosmopolitan, three are endemic, and four belong to the Indo-Malaysian region. Seven of the twelve thallose Jungermanniales are endemic, two are cosmopolitan, and the remainder occur in Southern Polynesia and the Indo-Malayan area. The writer collected sterile material of a large Aneura, apparently $A$. maxima, a species hitherto known only from Java and Sumatra.

Of the fifty-odd species of foliose liverworts listed by Stephani, the majority are endemic. Of the non-endemic species, only two are American, and one of these, as already mentioned, has probably been introduced through the agency of some migratory bird. All of the other nonendemic species belong to the Southern Pacific islands and Indo-Malaysia. It is sufficiently evident, then, that from the data available the hepatic flora is closely related to that of the Southern Pacific and southeastern Asia. 


\section{PTERIDOPHYTES}

According to Hillebrand, ${ }^{13}$ there are one hundred and fifty-five species of Pteridophytes, of which seventy-nine are endemic. As in other countries, a large majority of the species are ferns of the family Polypodiaceae. The most primitive of the ferns, the Ophioglossaceae and Marattiaceae, are represented by five species, three species of Ophioglossum and one each of Botrychium and Marattia.

Of the three species of Ophioglossum, one, O. pendulum, is widespread throughout tropical Asia and Malaysia, and also occurs in Southern Polynesia. The Hawaiian plants are smaller than those usually found in the East Indies, but are otherwise indistinguishable from them. The identity of the other species requires further study. It may be questioned whether Hillebrand's 0 . vulgaris is really that species. The single species of Botrychium is endemic, while Marattia Douglasii occurs also in Fiji.

The characteristic family Schizaeaceae comprises a single species, Schizaea robusta, also found in the Society Islands.

The Gleicheniaceae include three species of Gleichenia, the cosmopolitan G. linearis ( $G$. dichotoma), one endemic species, and one, G. longissima (G. glauca), a common species in the warmer parts of Asia and Australasia.

Five species of Trichomanes (three endemic) and four of Hymenophyllum, only one of which is known elsewhere, represent the filmy ferns (Hymenophyllaceae). The non-endemic species of Trichomanes are widespread species of the Southern Pacific region and Eastern Asia, while the only non-endemic Hymenophyllum, $H$. obtusum, is known elsewhere only from New Guinea.

The Hawaiian tree ferns, three in number, are all endemic, and belong to the small genus Cibotium, which has representatives in both the eastern and western hemispheres.

A very large majority of the ferns are Polypodiaceae, which include not only many endemic species, but also two endemic genera. One of these, however, Schizostege, is sometimes considered to be not distinct from Pteris. Of the non-endemic species, the great majority belong to the Australasian or Indo-Malayan regions. Two species only occur in America which are not found also in the Old World, viz., Asplenium fragile and Pellaea ternifolia, Andean species which reach Mexico and Texas.

The only representative of the heterosporous ferns given by Hille-

${ }^{13}$ Loc. cit., Introduction, p. xvii. 
brand is the endemic Marsilia villosa, which is apparently most nearly related to the Western American $M$. vestita.

The widespread Psilotum triquetrum and $P$. complanatum are common.

Of ten species of Lycopodium, six are endemic, two ( $L$. phlegmaria and $L$. cernuum) are widespread tropical species, while two ( $L$. volubile and $L$. serratum) belong to Australasia and the Malayan region.

There are three enedemic species of Selaginella and two others which also occur in Southern Polynesia.

\section{SPERMATOPHYTES}

The flowering plants of Hawaii show an extraordinary degree of endemism. According to Hillebrand, ${ }^{14}$ out of 584 species of Dicotyledons recognized as truly indigenous, no less than 500 are endemic. Of Monocotyledons 74 out of 121 indigenous species are endemic. This gives a percentage of 81.42 for all the spermatophytes and 85.62 for the Dicotyledons. There are many peculiar genera as well as species.

Undoubtedly the aboriginal immigrants brought with them a considerable number of plants, some of which have become naturalized. The staple food plant, taro (Colocasia), the bread fruit, banana and cocoanut doubtless reached the islands through human agency, and it is quite likely that the Kukui (Aleurites) and Ohia (Eugenia), which now form forests all over the islands, may have been introduced, as they are important economic plants found throughout Southern Polynesia.

The botanist is at once struck by the preponderance of Old World genera among the trees and shrubs of the Hawaiian forest. Aside from the Kukui and Ohia of the lower forest-species which are doubtfully indigenous-most of the native trees and shrubs, which do not belong to endemic genera, are members of extra-American genera occurring in Australasia or the East Indian region. The commonest tree of the middle forest region is Metrosideros polymorpha, a species common in New Zealand and throughout Polynesia. Perhaps next in abundance is the Koa (Acacia koa), an acacia of the phyllode-bearing type, most species of which belong to Australia. The screw-pine (Pandanus) and the related creeper, Freycinetia, are members of the exclusively Old World family Pandanaceae. The only genus of palms, Pritchardia, is confined to Polynesia. Other familiar Old World genera are Pittosporum, Gardenia, Santalum and Dracaena. Most of the species are endemic, and there are a good many endemic genera.

Some of the latter are remarkably developed and contain numerous species. Perhaps the best known of these are several peculiar genera of

${ }^{14}$ Loc. cit., Introduction, p. xvii. 
Lobeliaceae, forming one of the most marked features of the Hawaiian flora. Most of these are woody plants, sometimes assuming almost treelike proportions, twenty or thirty feet in height. The most important genera are Clermontia and Cyanea.

Climbing plants are relatively scarce among the indigenous plants. At the lower elevations species of Ipomoea and Passiflora as well as several leguminous creepers are often abundant, but these are mostly recent introductions.

There is a marked scarcity of conspicuous flowers among the native plants. First in importance is Metrosideros polymorpha, whose masses of crimson flowers are extremely showy. Some of the Lobelias have rather attractive flowers, and occasionally one encounters a native Hibiscus with large white, pink, or yellow flowers. Some species of Cyrtandra and Scaevola, genera abundant in the Malayan Islands, have attractive flowers, and one of the few native climbers, Strongylodon lucidum, at once attracts attention by its clusters of very showy scarlet flowers.

A marked feature of the Hawaiian flora is the complete absence of conifers, which are wanting throughout Polynesia except in Fiji. There are a number of other forms which one might expect which are also absent. Thus the widespread genus Ficus is entirely unrepresented, and the large family Araceae has no certainly indigenous representatives. Hillebrand gives but two species, both of which have almost certainly been introduced by man. The scarcity of orchids is also very striking, there being but three species known, these belonging to as many genera. Two of the genera, Liparis and Habenaria, are cosmopolitan, the third, Anoectochilus, being Polynesian and IndoMalayan. There are no native Scitamineae, although species of Musa, Zingiber, Curcuma, Canna and Hedychium have become thoroughly naturalized. The Iris family has a single native representative, Sisyrynchium acre.

Of the non-endemic genera a few are cosmopolitan, e. g., Rubus, Ranunculus, Lepidium, Silene, Geranium, Hibiscus; but a majority belong to the South Pacific regions and the adjacent Asiatic mainland. Such, for example, are Pittosporum, Pandanus, Freycinetia, Gardenia, Dracaena, Phyllanthus. A few genera are apparently of Australian origin, e. g., Byronia, Pseudomorus, Acacia. Among those suggesting a connection with New Zealand are Coprosma, Gunnera, Acaena, Lagenophora.

Among the most striking of the Hawaiian plants is Gunnera petaloidea. It grows in the wettest regions, at elevations of about 4,000 feet, where its enormous leaves arrest the attention of the most casual observer. This genus occurs in Chile and in the Malayan Archipelago as 
far north as Luzon, in the Philippines, and it is also known from South Africa and Abyssinia. The largest number of species is found in New Zealand, and the genus is not represented elsewhere in Polynesia.

The cold bogs, such as occur on the plateau of Kauai, recall similar bogs in the temperate parts of Europe and America. In addition to the tussocks of grasses and sedges, one encounters such familiar types as Vaccinium, Ranunculus, Viola, Geranium and even Drosera.

While the American element in the Hawaiian flora is much less evident than that of the southern hemisphere, there are several forms whose American relationships are unmistakable. The wild strawberry, Fragaria chilensis, is identical with the American species. The genus Sisyrynchium, except for the solitary Hawaiian species, is confined to America, and a number of the Compositae are undoubtedly related to Western American genera. Most of the genera are peculiar to the islands, but they are all evidently related to Western American ones. Thus Campylotheca is related to Coreopsis and Bidens, the "silver sword" (Argyroxiphium) is related to the Californian tar-weeds (Madieae), and the Hawaiian Raillardia is close to the Californian Raillardella.

A small number of other genera, e. g., Nama, Vallesia, are also apparently of American origin.

The most comprehensive attempt that has yet been made to explain the origin and distribution of the Hawaiian flora is that of Guppy, ${ }^{15}$ who accepts the hypothesis that the archipelago has always been completely isolated. His views as to the advent of the various elements of the flora are exceedingly ingenious and suggestive, but his conclusions cannot always be accepted without question.

Guppy assumes that the Hawaiian Islands first emerged from the ocean in early Tertiary times. This conclusion is based mainly upon Hillebrand' $\mathrm{s}^{16}$ hypothesis that the absence of conifers in the islands is due to the emergence of the latter subsequent to the period when conifers were predominant.

Following the studies of Treub on the restoration of the vegetation on Krakatau, after the great eruption of 1883, Guppy assumes that the establishment of vegetation on Hawaii followed the same course, and that the succession of plants was the same in the Hawaiian Islands as on Krakatau. ${ }^{17}$

That this conclusion is not entirely justified may safely be assumed. 1906.

15 Guppy, H. B.: "Observations of a Naturalist in the Pacific," 2. London.

${ }^{16}$ Loc. cit., Introduction, p. xiii.

17 Treub, M.: "Notices sur la nouvelle flore de Krakatau," Ann. du Jardin Bot. de Buitenzorg, 7, 213-223. 1888. 
The conditions in the two cases are very different, although there is a certain apparent similarity.

Krakatau lies less than fifty miles distant from Sumatra and Java, with their extraordinarily luxuriant vegetation, whence in less than twenty-five years (as the writer can testify from a visit made in 1906) an abundant and varied vegetation had covered the completely devastated island.

A comparison of Hawaii, over 2,000 miles away from the nearest mainland, and very much further away from the nearest habitat of most of its genera, with the conditions existing on Krakatau, is certainly justifiable only to a very limited extent.

Guppy assumes, as was shown to be the case on Krakatau, that the first immigrants were cryptogams of various sorts, ferns, mosses, lichens, and blue-green algae. The spores of these plants are supposed to have been carried by the wind. No details are given as to the relationships of these plants, as they now exist, except in the case of the ferns, where the statement is made that about half the species are endemic. It is assumed that the introduction of fern spores by wind is still going on, but no evidence of this is offered.

While there is no question that many species of ferns, e. g., the common brake (Pteris aquilina), have spread rapidly over the world, owing presumably to the ready transport of their spores by wind, this is not the case with many other ferns, such as Osmunda and the Hymenophyllaceae, whose delicate green spores very quickly lose their vitality and are quite unfitted for wind transportation over great distances. The same thing is true for many liverworts, and in this connection may be cited the case of Krakatau, where no liverworts had been recorded in 1906, although both Java and Sumatra are extraordinarily rich in these plants. It is therefore hardly likely that the presence of the filmy ferns, for example, can be explained by assuming that they have reached Hawaii from the distant Solth Pacific through the agency of air currents.

The great degree of endemism shown by the Hymenophyllaceae indicates that they belong to the ancient flora. Of the four species of $\mathrm{Hy}$ menophyllum three are endemic and the fourth is known elsewhere only from New Guinea.

Guppy believes that the peculiar Compositae of Hawaii were among the earliest immigrants and predicates an "Age of Compositae" antedating the influx of the plants from the southern hemisphere, which now predominate. The Compositae are much better developed in Hawaii than in Southern Polynesia, and have almost certainly been derived from America. Guppy believes that birds were the principal agents of transport; but in view of the facility with which the akenes of many Com- 
positae are carried by the wind, and the fact that the prevailing northeast trade winds would favor their carriage from America to Hawaii, it seems quite as likely that in this way the ancestors of the indigenous Compositae reached Hawaii.

As to the period of their arrival,- -assuming that the islands emerged during the early Tertiary,-it is hardly probable that at that period the highly specialized and probably relatively modern Compositae of California, e. g., Madia, Raillardella, had been developed, and these are assumed to be the nearest relatives of the Hawaiian composites.

In view of these facts it seems much more likely that the composite element of the Hawaiian flora is relatively modern, instead of being a remnant of an ancient flora. It is now generally believed that the Compositae are among the most recent plant types, and at present are still in a formative condition. They are not known in a fossil state back of the Miocene, and very few living genera are known as fossils. ${ }^{18}$ Their great development and rapid spread in modern times are due undoubtedly to their particularly perfect methods of distribution, either by wind or by animal agency.

The geological history of California is such as to indicate that most of: the members of its extensive and peculiar composite flora are recent developments.

The extremely specialized Lobeliaceae, which are so characteristic of the Hawaiian flora, are regarded by Guppy as among the early arrivals and, like the Compositae, of American origin. The relationship of these to American forms is, however, by no means so clear as that of the Compositae. While it is true that the Lobeliaceae are largely developed in America, especially in Mexico and the Andean regions, the family is a cosmopolitan one, and also abundantly represented in the southern hemisphere. New Zealand has a number of species of Lobelia as well as other genera, and there are numerous species in Australia and South Africa.

The endemic genera of Lobeliaceae and Compositae comprise about two-fifths of the endemic genera of Hawaiian spermatophytes, and these endemic genera are assumed by Guppy to be the descendants of the earliest immigrants. Of the other endemic genera which he thinks reached Hawaii at a later period, part are believed to be American, the others Malayan.

The rest of the flora he recognizes as predominantly Australian and Indo-Malayan.

Guppy is convinced that the most important agents in the distribution of plants throughout Polynesia were fruit-eating birds, and he assigns

18 Engler and Prantl: "Die Natürlichen Pflanzenfamilien," IV Theil, 5 Abt. p. 116.1894. 
a very important rôle to fruit-eating pigeons, which are so abundant in the Indo-Malayan region. He supposes that at some former period there was a very active dispersal of plants through bird agency, which ceased later for some unexplained reason.

There are very serious objections to these views, when the Hawaiian flora is considered. In the first place, we must assume an incredibly rapid flight and endurance, which would bridge the immense distance, for example, between Hawaii and South America or New Zealand, from which such genera as Gunnera must have come, according to Guppy's hypothesis. This genus, at present, comprises, as we have seen, about a dozen species, mostly found in South America and New Zealand, with a single species in the Malayan Archipelago and a couple in Africa. The species inhabit wet, cool regions-in Hawaii at elevations of about 4,000 feet. To suppose that this plant has reached Hawaii by means of some fruiteating bird coming from South America or New Zealand is certainly a strain on the imagination.

The next difficulty lies in the nature of the existing bird fauna of Hawaii. Aside from a number of American migratory shore birds and water fowl, practically all of the birds are endemic, and a great majority belong to a single peculiar family, Drepanididae, so modified that there is doubt as to its relationships. It is thought that the present bird fauna is descended from a very small number of original immigrants which reached the islands at long intervals and at some very remote period. None of the existing birds could have been responsible for the introduction of most of the plants, and if these owe their introduction to bird agency, it seems strange that none of the birds responsible for this should have left descendants in the islands. According to Guppy's hypothesis, these bird visitors were fairly numerous and not merely occasional stragglers, and if this were the case it is hard to explain the complete absence of such birds from the present fauna.

It might also be asked what explanation can be offered for this active migration. At present the migration of birds is due mainly to climate, and it is hard to imagine such changes of climate as would induce a migration from the southern tropics to the northern ones.

Guppy's theory as to the frequent bird visitors to Hawaii is also hard to reconcile with his reference to the existing birds which are supposed to be the descendants of a small number of immigrants which must have reached the islands "far back in the Tertiary." 19 But he elsewhere" states that the era of dispersal of the Malayan elements of the Hawaiian flora, which he thinks reached the islands through bird agency, was prob-

19 Loc. cit., p. 505.

20 Loc. cit., p. 520. 
ably post-glacial,- - long after the time at which the ancestors of the existing birds are supposed to have reached Hawaii.

The strand flora of Hawaii is notably poor in species when compared with most tropical regions. The principal ocean drift at present is from the northeast, but the likelihood of many species from northwest America, which might have reached Hawaii as drift, becoming established in such a different climate, is hardly probable. Just how such widespread species as Ipomoea pes-caprae, Scaevola, Vigna, Hibiscus and Terminalia reached the islands is doubtful, but very probably by drift, as many strand plants have special adaptations for carriage by water.

As we have already intimated, it is likely that a considerable number of species have reached the islands through the agency of wind. This is probably the case with some of the ferns, including the two American species; and we are inclined to regard this as probable also for most of the Compositae, and perhaps for other forms with very small and light seeds.

That any considerable number of species, except the littoral ones, have reached the islands as drift, is very improbable. Guppy suggests that certain genera, e. g., Erythrina, Canavalia, Sophora, which possess littoral species elsewhere but which in Hawaii are represented by inland species only, are descended from littoral species which came as drift, but which have become extinct. While this may be true, it seems rather improbable.

While recognizing the difficulties involved in any attempt to explain many perplexing facts connected with the origin of the Hawaiian flora, it seems to the writer that the evidence offered by the advocates of the theory of the strictly oceanic character of the archipelago is by no means adequate, as it involves assumptions, such as the extraordinary rôle of fruit-eating birds in seed distribution, which are, to say the least, quite incapable of satisfactory proof.

We believe that the evidence for a more or less direct connection with some continental area to the southwest is very strong, and the admission of such a connection will readily explain most of the difficulties that are involved in the assumption that the archipelago has always been completely isolated.

A study of the ocean depths would indicate that the whole Polynesian area might represent the remains of a former continental area, or series of large continental islands, connected at some time, perhaps in the early Tertiary, with Australasia and the Malayan Archipelago. Some such connection seems necessary to explain the great preponderance of Australasian and Malayan types in the flora of Hawaii, especially such forms as offer no ready means of transport by any known agency. 
There are abundant evidences of extensive subsidence in some parts of Polynesia, e. g., the Marshall and Caroline Islands, and Pilsbry shows that there is good reason to believe that this is the case also in the Hawaiian group. It may be that there was a marked subsidence in the latter, early in the Tertiary or possibly somewhat earlier; but it could hardly have been anterior to the later Cretaceous, as few modern angiospermous genera. were differentiated at that time. In the upper Cretaceous and early Tertiary, however, many existing genera are known to have existed.

A very extensive elevation took place in Western America during the early Tertiary, the great mountain systems of both North and South America dating from this time. It is quite conceivable that a corresponding subsidence may have occurred in the Pacific regions now occupied by Polynesia.

This theory would imply that the great volcanic masses of Hawaii are superimposed upon a much more extensive non-volcanic base, which formerly was above sea level. So far as the writer knows, there are no data available as to the thickness of the volcanic formations, or any knowledge of the underlying formations. It is therefore extremely unlikely that any fossils representing the original flora will be found (assuming an ancient continental connection), and we are perforce obliged to rely upon a study of the existing plants for evidence as to the original sources of the present flora.

The great preponderance of Indo-Malayan elements in the Hawaiian flora is sufficiently evident. Not only is the number of extra-American genera common to the two regions very large (about fifty, including Australasia), but a majority of the endemic genera are evidently derived from Southern Pacific or Asiatic types.

It may be assumed that these Indo-Malayan and Australasian genera of Hawaii are descendants of an original continental flora to which have been added the endemic genera derived from these, and a much smaller element introduced after the isolation of the archipelago. Among the latter are probably to be reckoned all the genera which are closely allied to Western American types, such as Sisyrynchium and most of the Compositae.

There are several genera whose nearest relatives are in South America, e. g., Nothocestrum, Kadua. The presence of these may possibly indicate a connection of South America with a former antarctic continent and perhaps with New Zealand, and these genera may be the remnants of once widespread types which have disappeared except at the two extremes of their former range. Perhaps the Lobeliaceae of Hawaii may be in the same category, as Guppy believes they are most nearly re- 
lated to Andean types; but in view of the wide distribution of the family, this seems questionable.

It is pretty safe to assume that the Hawaiian species of evident North American affinities have reached the islands as immigrants subsequent to their isolation. As there are a number of migratory birds, such as the golden plover, which regularly visit Hawaii, from Alaska, as well as various species of waterfowl, it may be that these birds have played a part in the introduction of some of these American elements of the flora whose seeds or fruits are not adapted to wind carriage. Among the genera which perhaps fall in this category are Rubus, Fragaria, Drosera, Vaccinium, Sisyrynchium. Such aquatic plants as Ruppia and Potomogeton may very well have been introduced by ducks or other water birds.

As to the Compositae of American affinities, as already stated, it seems more likely that their fruits have been wind-borne than that they were carried by birds. The prevailing northeast trade wind makes it possible that this has been one of the agents by which North American plants have reached Hawaii. It is hardly likely that the drift from the northwest American coast which occasionally reaches Hawaii has played any conspicuous rôle in plant introduction, as it is not likely that plants from Alaska and British Columbia would find a very congenial habitat on the shores of Hawaii.

The objection has been brought against the continental theory of the Hawaiian archipelago that certain types are absent, which on this theory one would expect to find. First in importance are conifers like Araucaria, Podocarpus and Agathis, characteristic genera of the Southern Pacific regions, like New Zealand, Australia and Malaysia. Another notable case is the genus Ficus, practically universally distributed through the tropics of both hemispheres. Another almost equally notable instance is the large family Araceae represented by but two species, both of them almost certainly introduced since the occupation of the islands by man. There are a number of other cases which could be cited, and these objections are real ones and not easy to explain.

Perhaps the most probable explanation is the possibility of the extinction of these forms, after the isolation of the islands, which made it impossible for them to be replaced. There are plenty of examples of such disappearance of plants from regions which they once inhabited. We have but to remember the many cases of Tertiary fossils, showing the former wide range of many genera, now restricted in their distribution. Sequoia, Taxodium, Liriodendron may be cited out of a long list of such genera, whose disappearance from many regions where they once flourished is amply proven by the fossil record.

Unfortunately there are no fossils in Hawaii to throw light upon the 
history of its flora, and we can only conjecture what may have been the agencies that have caused the disappearance of these missing types, assuming that they formerly existed. The most obvious explanation would be the extensive volcanic activity to which all parts of the islands have been subjected. Every region has at some time or other been covered with lava flows, and it is not unreasonable to suppose that many species, especially those of local distribution, may have been destroyed as the direct result of volcanic eruptions.

An indirect result of the purely volcanic nature of the present islands may have been a more gradual extinction of species which require certain constituents for their growth which are not present in volcanic soils. The almost complete absence of granitic or calcareous soils, for example, would practically prohibit the growth of many species that might very well have been present at an earlier period before the submergence of areas now completely covered by volcanic formations.

Another factor may also be considered, viz., the ravages of disease. Just as at present, in large areas in the eastern United States, the chestnut has been practically exterminated by the ravages of a fungus, so we may imagine species may have succumbed to similar enemies, and owing to the complete isolation of the islands could not reëstablish themselves.

Whether climatic changes in the course of ages may have played a part in the disappearance of any species, we cannot say. It is conceivable, however, that this factor may have played a part in the extinction of some of the original members of the Hawaiian flora.

We believe that a study of the relationships and distribution of the existing Hawaiian flora leads to the following conclusions:

1. The archipelago is the remnant of a once much larger land area which was connected more or less directly with the Southern Pacific area to the southwest now occupied by Australasia and the Malayan Archipelago. As the result of extensive subsidence throughout the Polynesian area, the Hawaiian Islands have been left in their present extremely isolated condition. The volcanic masses which constitute the whole of the exposed portions of the islands have been superimposed upon an extensive non-volcanic area now completely submerged. The isolation of the islands probably occurred early in the Tertiary.

2. The most ancient members of the Hawaiian flora are those derived from some continental area to the south, and comprise the more or less modified descendants of forms still represented by many Australasian and Indo-Malayan genera.

3. The American elements in the Hawaiian flora are of two kinds: First, those which have been introduced since the isolation of the islands, mostly from the west coast of North America, through the agency of 
wind or of migratory birds; and, second, certain genera allied to South American types, which very possibly may be residual forms from an era when there was a connection between South America through some extensive antarctic continent with New Zealand.

4. The absence of conifers and such widespread genera as Ficus, and a number of others which would be looked for on the assumption of a continental origin for the archipelago, is perhaps due to their extinction after the isolation of the islands. It is suggested that such extinction may have been due to volcanic eruptions, to changes in soil conditions, or ravages of disease. It is also possible that climatic changes may have been concerned.

Australasian-Malaysian genera occurring in Hawait, but not in America

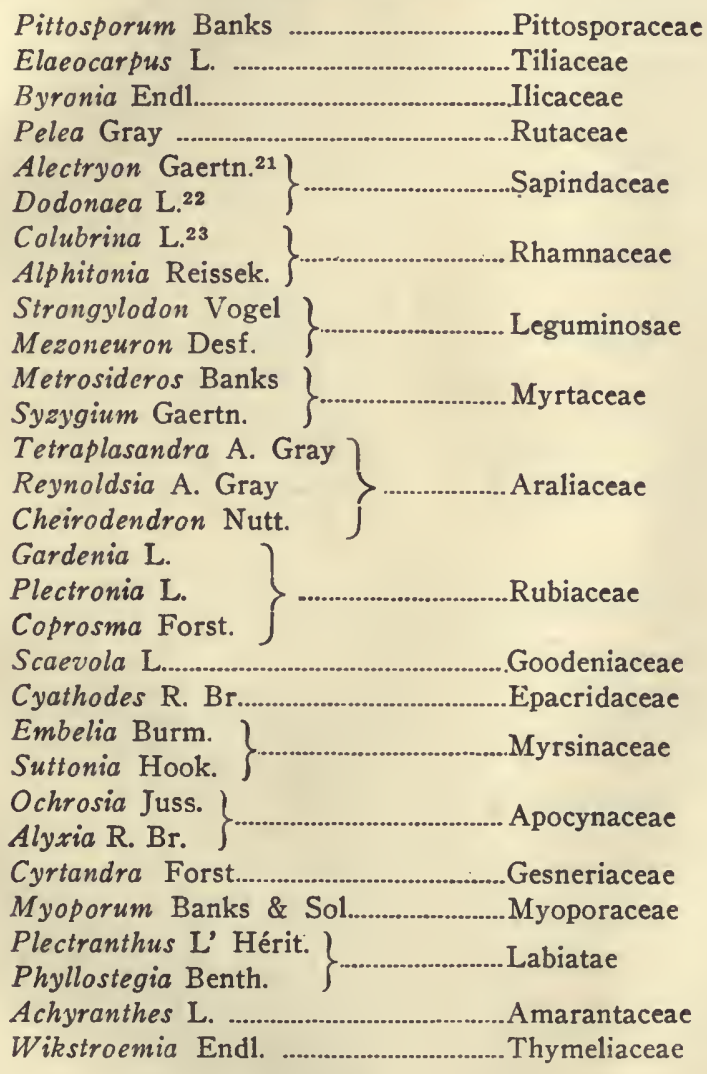

21 One cosmopolitan species.

22 One cosmopolitan species.

${ }^{23}$ One cosmopolitan species. 


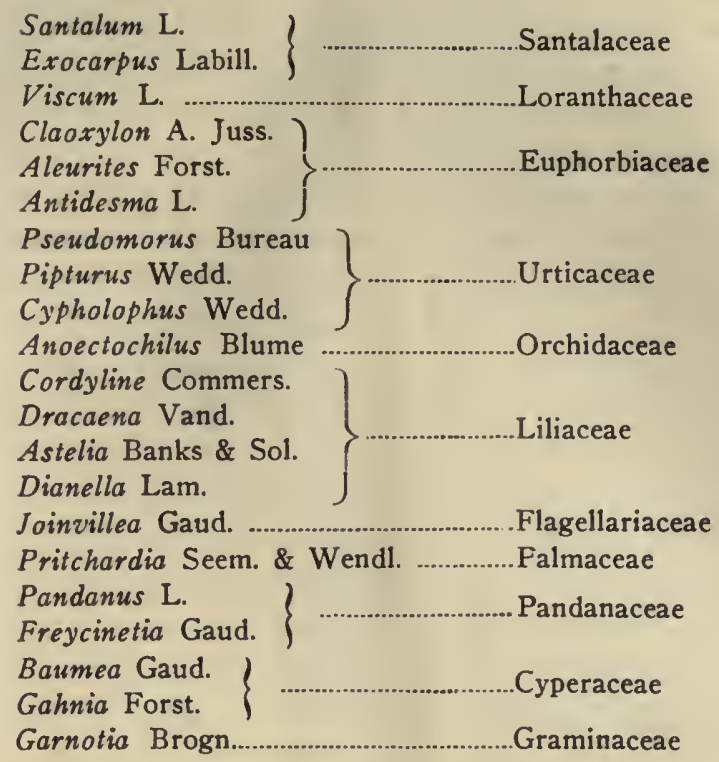
Hawaitan-American genera, not found in the Australasian region Genus Family Vallesia Ruiz \& Pav Apocynaceae Nama L: Hydrophyllaceae
Jacquemontia Chois Convolvulaceae Sphacele Benth. Labiatae Hesperocnide Torr. \& Gray Urticaceae Sisyrynchium L. Iridaceae

Pteridophytes 24 common to Hawall and the Australasian-Malaysian region, BUT ABSENT FROM AMERICA

Ophioglossum pendulum L.

Marattia Douglasii Baker

Schizaea australis Gaud.

Gleichenia longissima Blume

Acrostichum gorgoneum Kaulf.

Gymnogramme javanica Blume

Vittaria elongata Sw.

Polypodium Hookeri Brack.

$P$. samoense Baker

P. tamariscinum Kaulf.

$P$. lineare Thunb.

P. Spectrum Kaulf.

Phegopteris punctata Hillebr. Aspidium aristatum $\mathrm{Sw}$.
A. caryotideum Wall.

A. truncatum Gaud.

$A$. terminans Wall.

A. squamigerum Mann

Doodya media R. Br. Asplenium Nidus L.

A. normale Don

A. varians Hook. \& Grev.

A. contiguum Kaulf.

A. caudatum Forst.

A. horridum Kaulf.

A. spathulinum Hook.

A. Adiantum-nigrum L.

A. polyphyllum Presl

24 Nomenclature according to Hillebrand, "Flora of the Hawaiian Islands." 
Odontoloma repens Desv. Microlepia strigosa Presl $M$. tenuifolia Metten.

Pteris excelsa Gaud.

Trichomanes parvulum Poir.
T. meifolium Bory Lycopodium serratum Thunb.

$L$ Phlegmaria L.

L. volubile Forst.

Pteridophytes common to Hawail and America, but not found ELSEWHERE

Asplenium fragile Presl

Pellaea ternifolia Fée 


\section{THE FAUNA OF HAWAII}

The Hawaiian animals also show strong evidences of relationships with those of the Southern Pacific countries, there being only a small number of species that point to a derivation from American sources.

\section{MOLLUSCS}

The molluscan fauna is an extremely specialized one, and the land snails, which show a remarkable diversity, have been collected assiduously. According to Pilsbry, these are all ancient types, whose modern representatives are largely confined to Polynesia. More remotely related are species of the adjacent Asiatic regions.

"There is a marked absence of the modern land snails. There are no Helicidae and no slugs, in a word, none of the groups that have constituted all known continental faunas since the Eocene."

Pilsbry contends that these primitive snails represent an ancient fauna which has survived from a time when Hawaii was part of a continental area, connected with the Polynesian area to the southwest, where their nearer relatives are now found. "They represent early branches of the phyletic tree of the land snails."

Pilsbry thinks it extremely unlikely that these snails have been brought from outside to the islands, for if carried either by birds, by drift, or any other agency, it is remarkable that none of the modern snails have succeeded in reaching Hawaii. We must assume that transportation must have ceased before Tertiary time, for "otherwise it seems unaccountable that all dominant Tertiary snails of the continental areas are absent."

Pilsbry concludes that the distribution of the snails within the archipelago points to a former connection of all the islands into one large land mass. As a result of subsidence the islands became separated, Kauai being the first to become isolated. ${ }^{25}$

\section{INSECTS}

The total number of insects known from Hawaii is about $3,325,28$ of which 2,740 are supposed to be really indigenous. There is the usual very high percentage of endemism, and a majority of the species are related to Australasian and Indo-Malaysian types.

23 "Manual of Conchology," Introduction, p. xvii.

26 Perkins, R. C. L. : "Fauna Hawaiiensis," 1, Introduction, p. xii. 1913. 
It is impossible here to discuss all of the orders of insects, and it will suffice to select a familiar order, the Lepidoptera, which has received special attention. Perkins ${ }^{27}$ says that of 764 species known to occur in Hawaii, 700 species, or ninety-two per cent, are endemic.

The Macrolepidoptera have been studied critically by Meyrick, ${ }^{28}$ who states there are, out of 292 species, 261 (eighty-nine per cent) that are endemic, and that ten genera out of forty-nine are peculiar to the archipelago. Meyrick notes a remarkable degree of resemblance between the Lepidoptera of Hawaii and those of New Zealand, there being no Hawaiian families which are not also represented in New Zealand.

From his studies on the relationships of the Hawaiian Macrolepidoptera, and the geographical distribution of the non-endemic species, he concludes that the genera may be grouped under successive periods of time, and that they also indicate the geographical influences of each period.

To the earliest period belong seven genera, including 133 species. "Probably all of these must be traced to South Pacific origin, and a considerable land area (now submerged) between South America and New Zealand is postulated." 29

Second period-Five genera and eighty species,-one genus American and four Asiatic. "Possibly this period may coincide in time with the considerable extension of the Hawaiian Islands to the northwest which seems to have once existed."

Third period-Eighteen genera and forty-eight species. Of these, six genera are probably of New Zealand or Australian origin, five Asiatic, five American, and two doubtful. This would indicate "a nearly balanced equality of influences with circumstances much as at present."

Fourth period-Twenty-nine species,-twenty-one genera. Of these, nine genera are supposed to have been introduced artificially and there are seven cosmopolitan species. Of the remaining eleven species, seven are supposed to be of American origin and four Asiatic.

"The preponderance of the American element (I think a majority of the cosmopolitan species also came from that side) seems to be explained by the fact that almost all these species possess great powers of flight and find little obstacle in mere distance, but are by no means independent of the wind; the effect is therefore traceable to the influence of the northeast trade wind."

${ }^{27}$ Loc. cit., p. cxliv.

28 Meyrick, E. : "Fauna Hawaiiensis," 1, 123-275. 1913.

${ }^{20}$ Loc. cit., p. 132. 
The conclusions reached by Meyrick as to the origin of the Macrolepidoptera are in remarkable harmony with those of the writer derived from his study of the plants. Meyrick believes the more primitive members of the lepidopterous fauna have been derived from the Southern Pacific region, and as they are forms of relatively feeble flight it is difficult to account for their presence in the Hawaiian Islands except on the supposition that there was some more or less direct land connection. Meyrick assumes that they reached Hawaii by way of intermediate islands which have now disappeared. ${ }^{30}$

He notes that nearly all the forms of American origin are strong fliers, "and as the trade winds must always have existed, there seems no reason to suspect the previous existence of any intermediate islands between Hawaii and North America." 31

The case of these strong-flying American insects may be compared with our assumption that the ancestors of the Hawaiian Compositae also reached the islands by means of the northeast trade winds.

Muir $^{32}$ argues that the absence of a number of important groups of insects, especially some of the more primitive ones, indicates that the insects have all reached the islands since their formation; but as in the case of the absence of certain plants, this may perhaps be explained by assuming the extinction of these missing forms. Or it may be that some of the forms belong to types that have been differentiated at a period subsequent to the isolation of the archipelago.

\section{ARACH NIDA}

According to Simon, ${ }^{33}$ there are 101 species of Arachnida, of which seventy-seven are endemic.

Their relationships are mainly with Australasian and Malaysian regions, but there are some Nearctic and Palaearctic types, and an absence of certain tropical types which might be expected to occur.

\section{MARINE INVERTEBRATES}

Professor W. K. Fisher, of Stanford University, has kindly furnished the following statement concerning some of the marine invertebrates of Hawaii :

"The faunal position of the marine invertebrates of the Hawaiian Islands may be safely estimated from the relationships of such diverse groups as the hydroids, decapod crustacea, starfishes and sea-cucumbers.

${ }^{30}$ Loc. cit., p. 132.

31 Loc. cit., p. 133.

32 Muir, F.: Proc. Haw. Ent. Soc., 3, 198-200. 1916.

33 "Fauna Hawaiiensis," 2, 443. 
"In discussing the hydroids, Professor C. C. Hurtling says: "A study of the geographical distribution of the forms reveals unmistakable relationship with the Australian region. One indication pointing strongly to this conclusion is the great number of Plumularidae, which constitute about one-third of the species. The west coast of North America, and particularly Alaska, is characterized by a relatively poor representation of that interesting family, while Australia is one of the great centers of distribution of the typically tropical hydroids, the only region that rivals it being our own West Indian waters. ${ }^{\text {,34 }}$

"Of the brachyurous and macrurous decapods Miss Mary J. Rathbun says: 'The Hawaiian fauna is almost entirely Indo-Pacific, the islands forming the northeastern, as the Indian Ocean is the southwestern limit, for the majority of the species. This is true of the shore and shallow-water forms and in a lesser degree of the abyssal forms, of which many are cosmopolitan. Very little affinity to the fauna of the American continent is shown. ${ }^{35}$

"In regard to the shallow-water and shore species of starfishes and holothurians (or sea-cucumbers), which I have personally studied, the following general statement seems to apply: The starfishes are all tropical forms, and those which are not peculiar to the islands are chiefly Indo-Pacific, and comprise mostly wide-ranging species, some of which extend from the Red Sea to China and Japan, and thence to Australia. Considering the shallow-water species and those from moderate depths, which are peculiar to the Hawaiian group, we find their nearest relatives in the Indian Ocean, East Indies, and north of Australia. In a few cases the same species, from moderate depths, ranges into the East Indies, or as far as the Indian Ocean. Only one undoubted American starfish is found in Hawaii. There is no similarity in the faunas of the west coast of America and of the Hawaiian Islands.

"The same general facts are true of the holothurians. The shore and reef forms are unmistakably tropical, and the majority are common to the East Indies, Polynesia, Micronesia, Melanesia, and less than half to Australia."

It is evident that the fauna of the shallower shore waters is closely related to those of the Southern Pacific and Indian Oceans, and not with the much nearer American coast. As to the facilities for transportation possessed by these forms, the writer is unable to speak, but it is remarkable, if they have reached the islands by drifting, that this should never have been from the American coast, but always from the much more remote regions of Australia and the Indian Ocean.

34 Bull. U. S. Fish Comm., 23, 934, Part III. 1906.

sฐ Ibid., p. 830 . 


\section{VERTEBRATES}

FISHES

Dr. David Starr Jordan has informed the writer that the shore fishes of Hawaii are related to those of the Southern Pacific and not to American types. Such fresh-water species as are certainly indigenous have been derived from marine species that have migrated into fresh water and therefore throw no light upon the question of a possible former land connection.

\section{REPTILES}

No indigenous amphibia are known in Hawaii. This absence may perhaps be explained on the assumption that the isolation of the islands took place at a period prior to the time when the modern amphibia, frogs and toads, were developed. A similar condition exists in New Zealand, where but a single species is known.

Of the reptiles proper, there are seven species, four Geckos and three Skinks. They differ little if at all from widespread species of the Southern Pacific regions, and it is thought they possibly may have been introduced through human agency. It has been thought, also, that they may have reached the islands by drift.

\section{BIRDS}

The birds of Hawaii are of extraordinary interest, and have been carefully studied. Perkins ${ }^{36}$ says that except for a comparatively small number of migratory species, wide-ranging sea-birds and occasional stray visitors, all the species are peculiar to the archipelago. All the species of passerine birds are endemic, and most of them confined to the mountain forests.

Perkins records forty-nine species of passerine birds, of which all but one, a species of crow (Corvus), belong to genera peculiar to Hawaii. Forty of the forty-nine species of passerine birds belong to a peculiar family, Drepanididae, quite unknown outside the archipelago, and so specialized as to make its relationships problematical. Wallace ${ }^{37}$ thinks the family most nearly related to the Flower-peckers (Dicaeadae), widely distributed through Australasia and the Old World tropics. Gadow ${ }^{38}$ suggests the Coerebidae, an American family, as the nearest relatives of the Drepanididae; but in view of the predominance of Asiatic and Aus-

36 "Fauna Hawaiiensis," 1, 368-465.

37 "Geographical Distribution of Animals," 2, 277-278.

38 Perkins, loc. cit., p. 382. 
tralasian elements in the fauna, Wallace's view would appear the more probable.

The other passerine families are the Turdidae with a single genus, Phaeornis, and the Muscicapidae (Old World Flycatchers) with a single genus, Chasiempis.

Perkins believes that these forty-nine passerine birds are the descendants of six,-possibly seven,--ancestral species, of which possibly two gave rise to the Drepanididae. The extraordinary evolution of the species of this family and their highly specialized character indicate that they have been in the islands for a very long period.

Wallace says that the Drepanididae are "the remains of a larger and more varied family once inhabiting more extensive land surfaces in the Pacific."

\section{MAMMALS}

With the exception of a single bat, all of the mammals probably owe their presence in the islands to human agencies. 


\section{CONCLUSION}

It is evident, however they may have reached the islands, that the majority of both the animals and plants of Hawaii have been derived from the regions of the Southern Pacific, and have relatively little in common with the shores of the North Pacific, the nearest mainland.

While the ancestors of same of the species may have been introduced through the agency of wind or ocean currents, or by migrating birds, there are many more species, both plants and animals, whose transport over the great expanse of ocean lying between Hawaii and the nearest source of origin seems beyond the possibility of any known agency. The presence of these species can best be explained by the assumption of some former more or less direct land connection between Hawaii and the IndoMalayan region.

There is evidence of a great extension in comparatively recent time of the areas now occupied by the Marshall and Caroline Islands lying to the southwest of the Hawaiian Archipelago, between them and the Malay Archipelago; and this may point to a much more extensive land area at some earlier period. While much of the ocean between Hawaii and the South Pacific is 10,000 to 15,000 feet in depth, it is much shallower than that between Hawaii and North America. While a subsidence of such extent might seem improbable, the great time that has elapsed since the Tertiary would make this quite possible, even if it took place very slowly.

It is quite conceivable that very extensive subsidence occurred in the Pacific during Tertiary times, coincident with the enormous elevation of the land in western America, during which the great cordillera of North and South America was thrown up.

The evidence furnished by the existing fauna and flora is very strongly in favor of the view that the Hawaiian Archipelago represents the remains of the northern extension of some large land mass, connected quite closely with the lands of the Southern Pacific. Polynesia, as a whole, may be regarded as the fragments of one or more such submerged continental masses, upon which, as they subsided, have been superimposed the volcanic islands which now exist. 



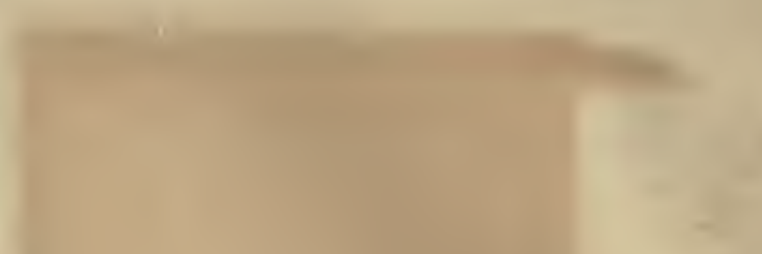




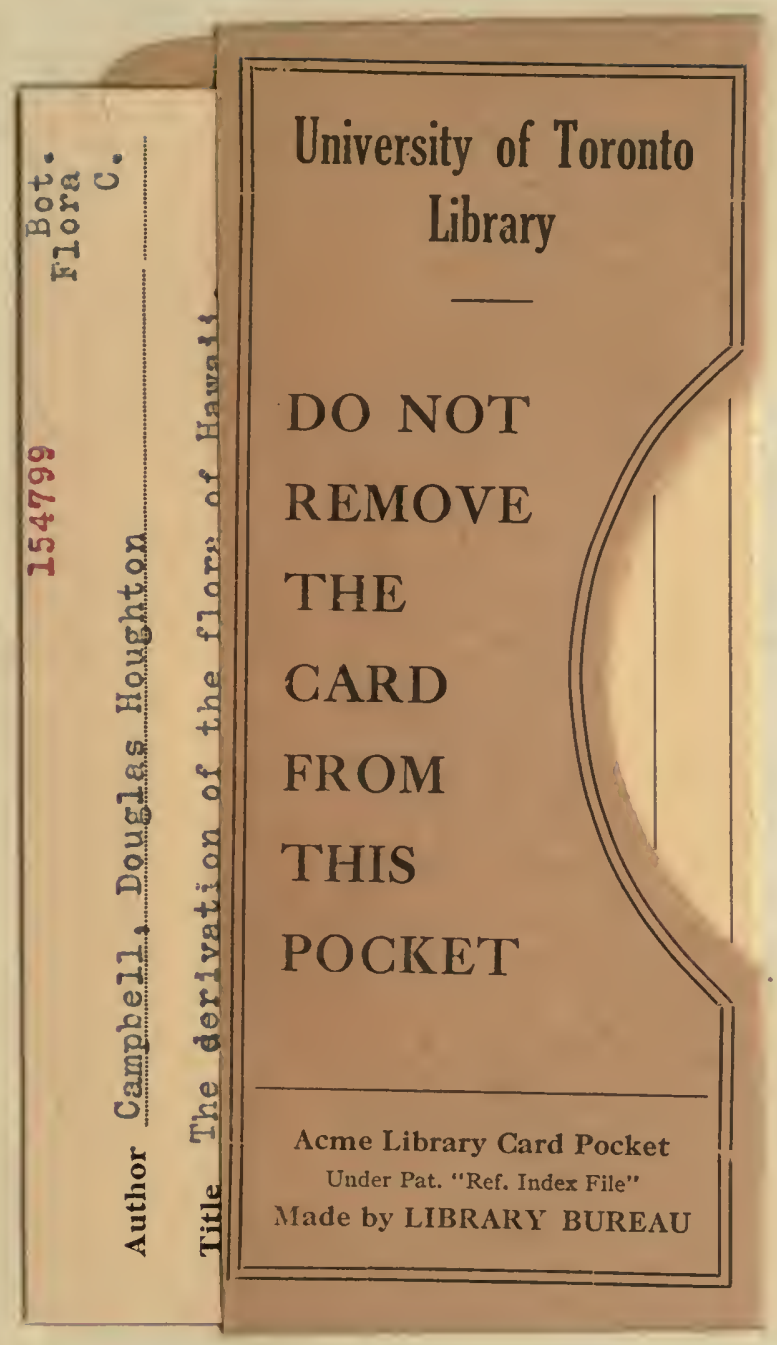


